\title{
Thinking in isiXhosa, Writing in English
}

\author{
Hilda F Israel \\ Nelson Mandela University, South Africa
}

\begin{abstract}
Acknowledging the presence of multilingualism within the South African classroom is now an accepted norm. Both teachers and students acknowledge their own mother tongue, as well as the language of instruction and assessment, which is usually English. What is not acknowledged is the personal and individual student experience of language: what do students feel as they negotiate words, phrases, sentences and paragraphs into their spoken and written communication? What is their experience as they think in isiXhosa, translate into spoken English, then convert into English for academic purposes? This paper examines the personal narrative of four students who describe their experience of being mother tongue isiXhosa speakers trying to succeed in an education context where the language of instruction is English. It relates their achievements, strengths and fears, exposing an underlying teaching and learning crisis that is silently present in every multilingual South African classroom. Their experience relates directly to re-educating the teacher in terms of methodology, assessment and classroom interaction. Negotiating personal experience based on language has the potential for diverse pathways for education in multilingual contexts.
\end{abstract}

\section{Introduction}

The South African classroom is multilingual now. The students can speak whatever language they choose, provided the teacher and their fellow students can understand them. However, the language of instruction is English, and assessment tasks are submitted in English. Examinations are written in English. The results of examinations are published in English, and the successful graduate gets a degree certificate written in English, and Latin. Other than the opportunity to speak their mother tongue in the education situation, the student has no other option but to try to improve his knowledge of English at conversational level in order to engage with teachers and other students. When faced with an assignment, the student has to analyse the question written in English, and then attempt to conduct a literature review on the topic by reading as many books and articles written in academic English. His assignment answers are expected to be written in academic English.
The teacher marks these assignments and as expected, the student who is competent in English scores a much higher grade than the student who is simultaneously learning and improving his English and attempting to pass assignments that he has to answer in academic English.

How does this context speak to the university teacher who has to evaluate the assignments submitted? What can the teacher do to advance the academic project so that it is of equivalent learning value to all students, despite the language challenges? How can the teacher empathise with her students and the processes that they have to go through before they submit their assignment answer to her? Will she ever understand their language journey generally, and their English language journey specifically? Will she ever understand what is happening inside the heads of her students as they sit behind individual desks, in long lines, in the examination room? Will she know what happens in those 3 hours before all are noisily ushered out - both English first and second and third language students?

I am a teacher of the English language. My students speak isiXhosa first language.

As a new teacher, it was always fascinating to watch a colleague's 2-3 year old child pick up random shapes and slot them into an alphabetical grid. With other teachers, we would watch how she correctly identified which piece to pick up in the order that was needed. We mixed them up, separated some into a different box and tried to confuse her. Each time, she would look at all, select the correct piece, and insert them in... A B C D. In trying to understand her thought processes, we as teachers were looking for ways in which to assist her learning, to challenge her limits and to adapt our teaching methodologies. This is the same scenario confronting us as teachers again, albeit in a different context. How can we adapt the teaching and learning situation for our second language isiXhosa students so that they too can participate as equals in a multilingual classroom? How can we understand what is happening "inside their heads" while they answer our examination papers in English? Four Honours students volunteered to try to explain their personal language journey, their experience as learners of the English language.

This paper reflects on the premise that many isiXhosa speaking students do not address the 
challenges that they experience in an English-first language education environment. The theoretical framework and methodology underpinning the argument is presented, followed by evidence supporting this in the form of real life language narratives of four isiXhosa speaking students. They are named Asanda, Bongani, Chuma and Dumani. Two broad themes emerged during the process of collating the data presented in their narratives. They were Teaching and Learning, and Academic Assessment. To establish focus on these themes, the student narratives and discussion are presented using them as headings. The last part of the paper recommends how the role of a teacher in the multilingual classroom can be transformed through simple, practical ideas that give dignity to the student as a person, and to isiXhosa as his mother tongue language.

\section{Theoretical Context}

The argument for the consistent implementation of multilingualism in this paper is underpinned by two theoretical foundations: Anti-Colonial Theory and Narrative Theory. Despite their differences, they work together to justify challenging the hegemonic role of English as the only language of instruction and assessment. The data presented through the narratives provides the evidence needed to take on this challenge.

Mangu [9], as cited in Mkize \& NdimandeHlongwa [11], clearly points out that curriculum transformation and the intellectualisation of African languages are essential if African universities are to play a critical, transformative and emancipatory role in society, commensurate with the idea of the African renaissance. Using anti-colonial theory, this paper argues that without deliberate inclusion of African languages in the education situation, the African renaissance would not achieve the transformation that it seeks within the higher education sector. Language, social and economic discrimination is invisibly woven into the experiences described by the students included in this paper. Their local language could have provided the academic success that they sought, but colonial norms were the embedded barriers to their progress. All learning frameworks emanate from communication through language, and transformation of the education situation therefore cannot legitimately take place without inclusion of their local language. Anti-colonial theory challenges the "nature of the traditionally accepted colonial experience as well as the consequences thereof" Mkize \& Ndimande-Hlongwa [11:11] citing Dei [5] and Wane [16]. They point out that colonialism destablilised communities, leading to their local languages being undermined and undervalued. Anticolonial theory evaluates, studies and understands the consequences as experienced by the respondents, calling for transformation of teaching and assessment methodology. This is the way forward to address the lived experience of the respondents, students who have to participate in an unequal teaching, learning and assessment context.

Narrative theory underpins the lived experience of Asanda, Bongani, Chuma and Dumani. Vincent's [15] recent workshop clarified the significance of narrative as a research methodology. She referred to Roland Barthes (1915-1980), who wrote that narrative is always present, in every age, place and society. All classes and groups have narratives - it is international, trans-historical and trans-cultural. Mishler [10] argued for how critical it was to listen to stories within qualitative interviews. Narrative theory is based on a sequence of events selected, organised and evaluated by the speaker... an account which is organised into a whole, with the significance of each event understood in relation to the whole, as clarified by Elliot [7]. The researcher becomes part of the study, having to reflect on her knowledge and understanding of the data being related. Aarikka-Stenroos [1] adds that the researcher chooses the point, purpose and topic of the study, as well as the theoretical and empirical elements that fit her framework. Deliberate reflection, as well as ethical and methodical challenges concerning anonymity and confidentiality have to be carefully addressed, and with greater sensitivity [7]. According to Bruner [4], narrative cognition seeks to affirm conceptual truth, and is based on the thematically and naturally progressing narration. The reader is affirmed in a more holistic way because affective and empathising elements emerge naturally in narratives. The reader experiences the events being narrated too.

Stories are related in order to make sense of one's self, and of others. So the narratives of the four respondents are sense-making tools to understand their experience of learning the English language, and the lived consequences thereof, specifically in the teaching and learning situation. Their stories are purposeful, the outcome of their reflection on their language learning experiences. This process of reflection and 'making sense' out of experience makes their stories a meaning making activity. Narratives are expressions of identity [14]. This paper emphasises that the 'making sense' exposes the inequality and injustice of the current language situation in teaching and learning. The teacher is therefore challenged to reflect on how language inequality can be addressed in a diverse, multilingual context.

Narrative theory identifies themes across its data. The focus is on the content told, rather than in the telling of the story. It is the researcher who develops the themes, which may come from the data provided by the respondents [14]. The reflections by the respondents in this paper led to the inductive identification of two broad themes: The Teaching 
and Learning Context and The Academic Assessment Context.

\section{Methodology}

Four students, all male, volunteered to participate in this study. They came from a class of seven (4 males, 3 females). Two were aged between 20-30, and the other two between 50-65 years. A questionnaire was the only method of data collection. Their narratives are credible because of the self referentiality technique which formed the basis of their experiences.

The excerpts included in this paper are taken from their reflective narratives. All are South African students who speak isiXhosa, and are reading for a BA (Hon) post graduate degree. They are currently living in the Eastern Cape. They are named Asanda, Bongani, Chuma and Dumani for the purpose of this study and to maintain confidentiality.

\section{Student Experiences of the English Language}

\subsection{Asanda}

Asanda is a full-time student between 20-30 years of age. His academic record so far has been very good despite many social and financial difficulties. He hopes to complete a Master of Arts degree specialising in language studies in the future. Teaching and Learning

For me learning the English language back in primary and secondary school was not a fun or boring experience because my only concern was to proceed to the next class the following year. I thought English is one of those languages that one needs to know the basics of, just to be able to answer questions in an exam. It only became apparent that English was an important language after I was compelled to take it as a module in my first year.

I remember how the lecturer was so passionate about the module and she presented it enthusiastically. That was the only point in all my academic years that a new perspective of the language came into view. I realised that if I needed to get somewhere with my studies I had to give knowledge of this language my attention because as the matters stand, English dictates how far you can go in life. If I were to write a motivational letter for a scholarship and I happen to commit too many spelling and grammar mistakes, chances are the application is likely to be declined on the spot.

I had a gap year before I began my undergraduate studies and my written English was a bit rusty (poor if you may), that lead to gross spelling and grammar mistakes and subsequently to my underperformance in my first semester modules. Fortunately, the solution to my problem was simple; learn English by familiarizing myself with English words by reading English novels. I regained my vocabulary and I ultimately did well in my second tests and passed all my first semester modules. I have never written a reassessment at any point in my undergraduate years.

I use English primarily for academic purposes and this limit my spoken English vocabulary in the following manner. When I am writing something of an academic nature, I am able to translate effectively from my mother tongue to English because I have enough time to think. When I am speaking, however, translating becomes a complex process as I first try to translate individual words from my mother tongue to English. It does not end there, when I have chosen those words from my English mental vocabulary, I still have to construct a sentence which must have meaning in a matter of seconds. In contrast to English, the process happens at a subconscious level when I speak my mother tongue because I do not feel like I am processing any information. My spoken English becomes even poorer when I am on the spot, but if I am familiar with the subject under discussion then participation becomes a bit easy.

\section{Academic Assessment}

I don't panic about writing an academic activity in English because I know I will have time to refine my work before the due date. This is different from a test or even a social interaction situation where the "due date" to refine your language is now.

When I am writing, I laterally construct a sentence completely before I put it down on paper. Otherwise there will be cancellations all over the script which is why I avoid wasting time writing something I am not sure of. It is more like the notion behind the phrase/saying "think before you act", except that for me it is more like saying to someone: think before you write. For the record, I believe I could have done way much better had I written all my academic assessments in my mother tongue.

\subsection{Bongani}

Bongani is a retired educator and school administrator. He holds post graduate qualifications in African Languages. He is now a full-time student. He grew up in the Eastern Cape. He is between 5065 years of age. He is continuing to study so that he can uplift isiXhosa among his local community members.

\section{Teaching and Learning}

When I was learning English in class I was taught by a Xhosa speaking teacher. She used to teach us English through Xhosa as result word order, sentence construction and pronunciation were not taken care of seriously.

You first think in Xhosa and translate to English feeling uncomfortable. Your concern what to be correct more than conversing and the meaning can 
also be distorted. Even a joke ends up with a distorted meaning.

You have a limited vocabulary which at times makes it difficult to understand the meaning of the subject content. You sometimes use the sources from other countries where the English language is slightly different from what we were taught.

\section{Academic Assessment}

Panic, frustration, nervousness, unable to grasp the content of the assignment and whether you are going to achieve the desired goal. You are unable to think well and to put the facts of the assignment into perspective. Your sentence and paragraph sequencing becomes haphazard.

You construct your answer by thinking in Xhosa and then put it in English which is time consuming. Examinations are a stressful situation - you may misunderstand what the question requires.

\subsection{Chuma}

Chuma is a teacher/minister who is studying isiXhosa in order to help his church members to understand their faith better. He is between 50-65 years old and holds leadership positions within the presbytery. He has vivid memories of learning the English language, and commented on this from the point of view as a teacher as well.

\section{Teaching and Learning}

Both my parents were teachers, and my grandfather was a principal. I recall being asked to go to the shop and speak English there. I was asked to go to buy one guava, and asked - How much guavas one? When I got back with it, the family said: Now you can speak English. My mother was my language support. My father was an isiXhosa teacher. He made me proud to speak isiXhosa.

My vocabulary grew because of my teacher, $\mathrm{Mr}$ N. He would say, no, this is how you say the word. Do not try to Xhosalise your English words. He corrected our pronunciation. We loved him. We began emulating him, even in his way of speaking.

We learned English by purely trying to memorise for big debates in school. And to impress girls with our big terms. We were taught more by compulsion. If you missed the right verb you were punished and the cane would be there. Then we had to write an English composition, and you became the laughing stock of Form 1. So we decided as boys to try to speak and write better English. We could hear it, but it was difficult to put what you had in mind on paper.

I went to seminary - everything was in English, nothing was in isiXhosa. We were studying for ministry. We had to compete with both whites and coloureds when writing our English essays. That's how we learned. When we played rugby we had to speak English. We had to play Fort Hare, and we had to prove to ourselves that we could communicate with people at university.
I process my words inside my head - and learned from presbytery meetings as a minister. There were times when I had something to say, I had something that I wanted to challenge, but because of not being sure of my English, I would rather die with it than ask it. It was only when I got used to my presbytery that I became free to ask questions the way I wanted. It was after university and presbytery that I got used to being free. As I write and report in English, I gained confidence.

I was teaching history. I wanted to say the right things, speak the right things. Fear stops you. It's knowing the right way of saying things, but you hear somebody not saying the right things. You ask yourself lots of questions before you check yourself, if your English is correctly spoken. Am I going to say it right?

IsiXhosa is always spoken at home. I insist. My children have all gone to multilingual schools. I made sure they know that isiXhosa is our home language.

In the township, the people speak English and use the mannerisms of English people. In church, I speak both isiXhosa and English. I feel that our children are taking English as a subject and some norms from English people which do not match with our norms. For eg. they do not show respect when they address their elders. My son has to say Tata to people of my age. It's not Mr B, but Tata B. They speak carelessly, with little respect.

I speak to my student colleagues during a lecture. They hear what I have to say. You just follow the classroom norms. It is good to speak so all understand. I don't mind making mistakes here.

When you listen to a person, it automatically goes to your isiXhosa register. Because you know some English, you able to arrange your answer in English. When you speak of equivalence, you start by breaking the word equally, so you start working from there. You want to interpret it in your language, isiXhosa, in your mind so that you get the picture. A process is taking place - listening in English and to concretise it, it has to pass that register. Happens simultaneously at times, there are other times when I break things slowly, when I need more time to refer to my register.

When I listen in isiXhosa to interpret into English, I don't do all this. Language flow spontaneously happens. I grapple sometimes. We are particular about the right word - to say something almost exactly. There is sometimes a delay in speaking as you think first.

\section{Academic Assessment}

$\mathrm{Mr} \mathrm{N}$ was my matric teacher in English. He would encourage us. He impressed us. Principal RP spoke as if he was singing in English, he was so fluent. He never laughed at us.

When I do an assign I can read the question, but I can't make head or tail sometimes. What is this 
saying - so I go back to isiXhosa to find meaning then back to English. When I write an essay - how should I approach it? I equate words in isiXhosa from English. There's a conversation in isiXhosa in your head in order to answer an assign in English. The problem is not to Xhosalise the English. It's true that there is a whole lot that I am doing in isiXhosa in order for me to be proficient in English.

Revising my answers can be confusing too. Having written it, you want to produce a work that is worth it, so you read it. isiXhosa and English get intermingled in your mind, so you go back to your register.

English has its own rules. This doesn't lull isiXhosa. I take my idiom from both languages. When it comes to answering a test, it's in accordance with that register again.

In the exam room, I interpret the English question until I know its meaning. The strength is to know it in your own language first. You begin to be able to expand on a certain topic because you know this. You link it to the concept that you already understand. How else can I think about this? And then that goes to your isiXhosa register again.

There's a time delay in exams only if you can't get the register. You want to find the precise meaning of a word. Eg. Overview - phezulu - I worked out that it means I can't dig deep into it. That clue needed to answer the exam question is important. I need a word to make that meaning. Now even to preach, I meet with my inner self to prepare, to be correct.

Nothing is done simply. What is simple English? A word can be treated superficially, but can have different meanings in isiXhosa. When I go to that register, then degrees of intensity come up.

In an exam, it does take time to get the meaning of a question first. The right meaning. English speakers are better off - they don't have to find meanings of words.

We should help especially those students who come from rural schools. They struggle. Many students are rote learners. Their schools are not multilingual. Give them extra time to answer their exams. They need to connect with their register. They actually answer questions that are not asked. They never give meaning to each word in the question. So they answer off the question.

They should be able to write in isiXhosa or in English. And given more time. Questions should be set in both languages.

My belief is that matric results are not a true picture of what is happening. Advantaged schools score high. Our kids are "Half deaf, half dumb." They hear, but they don't hear it all. When it comes to answering, they can't say precisely what they want to say. At these multilingual schools, the children are taught and they play in English. They are informally learning the language, so there are situational benefits.

Theorems - do the kids in rural schools understand what they mean? Translate them - after that the kids will find examples themselves. Translations would make wonders in learning. Memorising and application are what they do most times, but these are both disconnected.

Reading will definitely help as the two senses work - words are seen and heard. We should learn new words in a way that they must stick in your brain. We are not readers. Making our children to be readers will change everything. That's the turning point.

\subsection{Dumani}

Dumani is progressing well as a student and pastor within his local community. He is between 20-30 years of age and holds a BA degree. He has also studied music. He enjoys speaking isiXhosa.

\section{Teaching and Learning}

I have a very bad history in learning English language because my high school teacher demotivated me no matter how hard I have tried. She has taught me for fully four years of my high school since grade 9 up to grade 12 . When I was trying to write with my limited vocabulary she will crush it and call trash. When I change style and decided to consult dictionary she will say I have stolen something on magazine. I was known as one of the stupid learners when it comes to English. I still remember one of her marks as if it was yesterday, "I don't know why teachers are appreciating and hailing you as good student in Mathematics and IsiXhosa while you cannot perform in my subject." Remember in our high school a child is measured by how fluent with English as to be seen as best student.

There was no future since to me even to be admitted at varsity was great shock to many of my teachers. When I arrived in varsity I did education where I majored with isiXhosa and Music but I didn't love music. I was financial excluded but on my second return I did B.A then I majored with IsiXhosa and English. My confidence of English was raised by my lecturer, Mrs $\mathrm{B}$. She influence by saying there is no need to have particular accent when you speak English because we learn it we didn't acquire at a very tender age. I felt in love with English to the point I had level 3 of it. Now that I saw there is nothing more important about I will grow with it. One of the success I will never forget is to see one of my former classmate at high school who is doing her Masters said to me, "I am so happy to see you progressing in life after the negativity that was said to you by our teachers but now you are doing Honours. I wish to call our English teacher to tell her your success as compared to one of us who 
were her favourite." Whenever I meet with English lecturers we speak English although they are Xhosas.

I had bad attitude when someone who is going to speak English whereas he is Xhosa speaking too because my view was why we cannot speak our own language because we need to preserve and protect it from dying. Many would argue that as for us to master English we need to practise and read it every day but my view was why do we have to care about mastering someone's language that he/she does not even know how to greet us in isiXhosa. Now that we are in multilingual society I do not have problem but it must not be Nguni languages because they very related. When I visit amaNdebele in Mpumalanga I use isiXhosa and Ndebele than using English because I promote that they must use their mother tongue as to protect, preserve and develop their own language. In social media it is most preferable way due to the fact that cellphone and computers has autocorrect mode that is in English. It takes time when you write in indigenous language because it needs prove reading as the autocorrect can't pick up wrong word. I don't have problem with English as I can communicate well now but there expressions that you cannot translate well from isiXhosa to English. There are terms that you cannot translate to English but you can only borrow them not sure about their equivalent translation.

\section{Academic Assessment}

It is little different when your class is multiracial because you care about other people whether do they understand what you are saying and will your information be helpful in their lives. When we understand each other I don't feel uncomfortable to speak English when we discuss, because even our churches today are using English to preach in township or location of indigenous people. I noticed a lot of grammatical errors in their interpretation and my view is - why did we use English in the beginning because we hear each other in our native languages?

The problem that I have is that you need to research in English and what is happening in your mind is the translation of knowledge from English to isiXhosa as to make sure that you understand them. When you do your assignment you think in isiXhosa and translate it as to write in English. It makes a lot of mistakes because you need to care about English grammar and rules. The most time you spend on editing and making sense of your assignment.

It happened through my whole academic life where I write and the invigilator will announce timeup. I do believe it is our system now because we grew up with it. It was not a matter of choice but the matter of being forced. I would even say we did not even see anything wrong with it. The other challenge it is when you don't know that particular word in English that has been used by the examiner. That one frustrates a lot but we contextualise it so as to move on.

\section{Discussion}

The experiences of Asanda, Bongani, Chuma and Dumani relate directly to re-educating the teacher in terms of methodology, assessment and classroom interaction. Negotiating personal experience based on language has the potential for diverse pathways for education in multilingual contexts, rather than language being the basis for social discrimination and inequality.

The role of the university language teacher has traditionally been to focus on the module purpose and content, with broad distinction between linguistics and literature. Specialised focus was developed at post-graduate level. Communication modules served to meet the needs of National Diploma qualifications, with language development being an integral part of competent communication in how one speaks, writes and reads. Degree qualifications did not require a mandatory language module. The underlying assumption was that the matriculated student entering university had a competent knowledge and understanding of the English language, and would develop this into Academic English as she would progress towards completion of her qualification. Teaching the student English as a second language was not part of the curriculum.

Post-apartheid academic institutions have rightfully changed their demographics in terms of staff and students. The pace of such transformation is questionable, as is the transformation of the curriculum. The 2016 \#FeesMustFall movement emphasised further the need for curriculum transformation, as well as the need for African languages to be recognised and more visible in the higher education sector. In other words, the multilingual classroom is already a reality for the students. In other words, teachers have to recognise this opportunity and see multilingualism as the strength that it is, adapting their teaching methodology and assessment modes to create an environment for optimal learning to take place for the benefit of all students.

Okal's [12:227] work citing Lyons [8] on the integration of multilingualism within all sectors is based on the fact that languages do not function in a vacuum, but are embedded within culture and society... language is thus a "sociolinguistic, an ethno linguistic and a psycholinguistic issue... language relies on society, culture and mind." It is the experience of learning different languages that changes the attitudes, skills, beliefs and outlook of people, enabling an expanded world view. However, what the respondents describe is not a voluntary, enjoyable learning of the English language because 
multilingualism within our academic institutions is not recognised in the way that Okal [12] describes it. Their narrative is based on the exclusive domination of English for academic success, and the simultaneous undermining of isiXhosa in their pursuit of this success. Not only is their personal language undermined, but they are expected to think and behave in an anglicised manner as well meaning that their African culture is being destabilised too, impacting on their identity and pride as a Xhosa person.

"Multilingualism provides an insight into the understanding of different cultures and experiences hence a multilingual becomes multicultural in nature" Okal [12:227]. If the narratives of the respondents are indicative of a need to mould a different, affirming attitude to African culture and languages, then it is the multilingual classroom that would affirm such values, and induce the change that is clearly needed.

\subsection{Teaching and Learning}

The childhood narrative of learning the English language was vastly different for each of the respondents, yet similar in that they had to learn it at school, then go back home to their mother tongue. English was seen as a school subject, not serving any personal and practical reason. Ironically, the older respondents spoke of how this has now changed in that their children and grandchildren were learning English as a first language, and sometimes isiXhosa was almost unknown to them. English is seen as the most important language now, and how one speaks it is indicative of class, status, education, refinement and success. Asanda's experience captures this when he says: "English dictates how far you can go in life." Dumani accepts that there is nothing more important than his knowledge of English as this will determine his growth as a person.

The purpose for learning English amongst the respondents was both sad, and yet informative, in its reflective context. Asanda wanted to simply pass into the next grade at school, so he learned just enough of the language to answer examinations every year. It was at university that he realised that it was also important for the success of his career and scholarship. However, he saw little purpose in it outside of academia. Dumani did not see any clear purpose in improving his English because he was of the view that it was not his language, so why should he master it? More so, English came from the colonisers, and their descendants did not care to learn his isiXhosa, not even to greet him in his language. The lack of respect for his language was felt deeply. Chuma has more positive memories of his purpose in learning English. He and his school friends were determined to learn the language because they loved their teacher and wanted to impress him, to be like him in their manner of speaking and behaving. They wanted to do well in school debates, and on a social level, to impress the girls. He credits his situational context as a key factor in his purpose for learning English, and for his aptitude in acquisition of the language. At his seminary, all spoke English. All were assessed in English. He had to prove that he was as equal to the task as the white and coloured students. When they played rugby as a team, they had to communicate in English. When they played against the Fort Hare University students, they had to prove that they too could talk competently in English.

It is interesting that the respondents learned English and isiXhosa, and were taught English by isiXhosa speaking teachers. Bongani reflects that this led to him not learning word order, sentence construction and pronunciation. Chuma, on the other hand, remembers learning English by compulsion, with the cane as his second instructor. If they spoke incorrectly, they became the laughing stock of the class. Punishment was to write an essay in English. However, he notes that they depended on memorising words; they could hear them, but not write them.

The lived experience that Dumani remembers shows what a profoundly negative impact his teacher had on him. She demotivated him no matter how hard he tried, and crushed his efforts at improving his vocabulary. She accused him of copying sentences from magazines. Significantly, Dumani thus came to these pertinent conclusions about himself: he was known as one of the stupid learners when it came to English; he had no future because he was 'stupid', because he was not fluent in speaking the English language. Note that this was despite him experiencing academic success in isiXhosa and mathematics. In his high school, a child's intelligence was measured by how fluent he was in English. Mkhize \& Ndimande-Hlongwa [11:15] confirm this perception: "... the use of exoglossic languages creates elitism. The use of indigenous African languages is associated with inferiority and being 'uncivilised' while mastery of colonial languages is thought to be an indicator of superior intellect and civilisation par excellence."

Learning to speak in English was and still is easier for all four respondents, with time to think being a key factor in how correctly they spoke. Dumani and Asanda pointed out that mental translation is a natural choice, but there are some words and expressions that are difficult to translate from isiXhosa to English. Asanda finds this a complex process, where he has to translate and simultaneously try to construct a meaningful sentence for his audience to appreciate his contribution to the conversation. He does not have this difficulty when speaking in isiXhosa, stating that "the process happens at a subconscious level... I do 
not feel like I am processing any information." Chuma confirms this experience as well. Speaking is easier if one is familiar with the subject under discussion. Bongani feels uncomfortable when speaking in English because he is screening the words in isiXhosa first. His focus is not on the conversation, but on how correct his vocabulary is so that his meaning does not get distorted.

Dumani is the one respondent who raised a real and pervasive factor in his narrative of learning the English language - that of accent. His confidence in speaking was raised when his teacher clarified that one does not need a British accent when speaking English. Accent is becoming another critical discriminatory indicator of who is civilised and who is not. Conversations with my students reveal how they judge each other based on how they sound, with those growing up in multilingual, mixed schools being seen as superior and more confident. Those with heavy African accents are looked down upon, and openly ridiculed. Such students themselves admit that they are ashamed of how they sound, especially when they hear how clearly the others speak. They see themselves as being deprived from growing up in an ethnically mixed school with a multilingual teaching and learning environment. Chuma referred to this as them not having opportunities to informally learn the English language, so they do not inherit the situational benefits.

Confidence in how one speaks gives freedom. Chuma relates how he became free to speak English among his multiracial congregants. It took many years of not speaking. Often, he had something to say, something he wanted to challenge... but because he was unsure about his use of English, he "would rather die with it than ask it." He wanted to say the right things, but was fearful whether he was going to say it correctly. He knew the rules, but on hearing somebody speaking incorrectly, it made him more introspective and insecure. He kept cross-checking in his mind whether he was going to say it correctly, and if not, then it was better not to speak. Listening carefully enabled him to go to his isiXhosa register, so he would think the words in isiXhosa first until the process helped him to concretise the meaning. Pertinently, this does not happen when he has occasion to do interpreting from isiXhosa into English. Language flows more spontaneously then. Confidence comes naturally.

Speaking English in educational contexts was a more individualistic experience for the respondents. Dumani meets with his Xhosa lecturers who taught him English, and they all choose to converse in English rather than isiXhosa. He sees this as a dilemma - why shouldn't they be conversing in isiXhosa, because this language needs to be preserved too.

Speaking in a multilingual and multiracial post graduate class was unique for the respondents. Each took care to ensure that other students understood what they were saying. None felt uncomfortable to speak in English because the fact that they were all students proved a leveller, they were all learners in this context. Chuma did not mind making mistakes here. Dumani was comfortable because he felt that English, whether correctly used or not, was just the common language being used by everyone in many contexts, even among second and third language speakers.

Having teachers whom they respected proved an incentive for Asanda, Chuma and Dumani in their language experience. In the university classroom, affirmation comes from respect as well - from the teacher who identifies the needs of his students and meets them at that point of need. Verbal feedback in class, in any language, should aim at motivating the student to try to improve her English usage without undermining her isiXhosa accent and influence.

Feedback on assignments from lecturers should encourage thinking and writing in both languages when relevant, ensuring that the dignity of the individual and the language is maintained. The respondents noted that it was the encouraging, passionate teacher who made a difference in their learning of the English language. Key to her understanding of the student is the acceptance that the student's use of the English language is no indicator of his intelligence, aptitude or aspirations. Both Asanda and Dumani made a radical change in their attitude to English because their university lecturers revealed its value as a global language, and affirmed that they were progressing in it as a second language. Purist pronunciation and accent was secondary to competent, communicative use of English.

Chuma's father, an isiXhosa teacher, made him proud to speak his mother tongue. Today, he insists on isiXhosa being spoken at home, while also ensuring that his children benefitted from the situational context that he believes is essential for a child to learn a language. He is critical though of language and culture being blurred, having noticed how some Xhosa people speak English and adopt colonial mannerisms as well. He illustrates what he sees as a lack of respect being shown by younger people when they address their elders, for example, saying Mr B rather than Tata B. Tata has so much more significance in isiXhosa register than 'Mister'. Akeem [2] confirms Chuma's identification of discord between language and culture, arguing that such disconnections in society stifle development, especially where groups share a common language but not the same culture. Communication barriers increase and the people suffer economically, socially and politically.

The situational context recommended by Chuma is multilingualism in practice. Parents should expose 
their children to multilingual environments as early as possible. Okal [12:226] points out that:

Multilingualism practice tends to create the development and general acquisition of cross-cultural communication skills... people tend to learn different skills of the languages in place especially speaking, reading and even writing. These crosscultural communication skills enable one to gain both the communicative and discourse competencies. When one knows the official language and perfectly speaks the indigenous languages then the person will be able to synthesis knowledge and express it accordingly. It is therefore necessary to include indigenous languages in education so as to realise the benefits of synthesizing and clearly expressing knowledge... children with parents constantly speaking different languages grow up being equally fluent and comfortable with the two home languages and can even learn a third and fourth language... this is also practical in the classroom contexts whereby students who are exposed to many languages will tend to be intellectually flexible.

The multilingual learning environment stimulates the cognitive development of a child. Multilingual children are "superior lateral thinkers, have a greater social adaptability, their thinking and reasoning skills are better, and their cognitive abilities are also greater" Okal [12:227].

All four respondents experienced a feeling of disempowerment, insecurity and fear when not speaking in their isiXhosa language. Alexander [3] affirms that it is empowering to use the language which one speaks best in any situation. Not being able to do so is definitely disempowering. This is why he promoted mother-tongue education as the foundation of all democratic institutions. Research by Simkins and Patterson [13], as cited by Alexander [3], comments on the causal significance of English as the medium of instruction:

... social and economic variables at the individual household level do not play an enormous role in determining performance, with the exception of the language variables. Pupils whose home language is an African language are at a considerable disadvantage in the language of instruction (read English N.A.) by the time they reach Grade 11 if the language of instruction is never spoken at home. This can be offset somewhat if the language of instruction is spoken sometimes at home and it can be offset considerably if the language of instruction is spoken often at home [13:33].
Alexander [3] concludes that their study validates the argument for mother-tongue education because it proves a causal relationship between the language of instruction and the students' success. Asanda's words resonate most appropriately with this conclusion: "For the record, I believe I could have done way much better had I written all my academic assessments in my mother tongue."

\subsection{Academic Assessment}

Academic assessment takes place through oral presentations, and the writing of assignments and examinations. Speaking has already been discussed in the teaching and learning context, with the exception of focus on fear, apprehension and nervousness when having to speak in English before an audience. Not only does the teacher expect competent use of technology, the creation of professional power point slides and team effort in the presentation, but one has to speak confidently before one's entire class. The translation coping mechanisms mentioned were used by all four respondents to speak during presentations. Their narratives, however, focused on class discussion during post graduate seminars.

It was the writing of academic assignments and examinations that challenged the respondents in their experience of language learning. Writing is critical because it is the form of assessment that determines one's passing or failing a module, and subsequently has implications for one's academic, career and economic success.

Writing answers to an assignment is viewed as easier by all four respondents because time is a critical factor. They all translate the question into isiXhosa, think the answer out in isiXhosa, and then translate into English. Many language errors occur but, as Dumani relates, the most time is then spent on editing and making sense of your answers. Bongani goes through an initial phase of panic as he tries to grasp the content of the assignment, wondering if he will reach the desired competency in sentence and paragraph construction. Asanda recognises that time allows him to refine his assignment answers, and he works on it long before the due date.

The narratives on which this paper is based serve to stimulate and further the transformation of assessment methods not just for the language classroom, but for teachers of all subject content in all qualifications. Asanda has trained himself to do "lateral thinking" in an examination, a coping mechanism that works for him as he wants to save time so that he answers the question in the best form of English that he knows. He does this in all his examination papers, be they language or sociology or psychology. He acknowledges that this robs him of time to answer as effectively as he would do in an assignment, but who dares to challenge the 
examination system? Dumani says that he did not choose the examination system, but was forced into it to the point that he now accepts it. He recalls how he has to endure the announcement from the invigilator that time is up, knowing that he is never ready to hand in his answer script. He accepts this because it is the norm, but who set this norm? With what do we replace it if we challenge it?

Bongani describes how he translates the answer from isiXhosa to English when he answers examination questions. If one had to take his system a step back, then it can be assumed that he first translates the question into isiXhosa too. He added that he has done this over many examination subjects through his life, and that this is time consuming. Chuma points out that this is still being done, especially by students who come from rural schools:

We should help especially those students who come from rural schools. They struggle. Many students are rote learners. Their schools are not multilingual. Give them extra time to answer their exams. They need to connect with their register. They actually answer questions that are not asked. They never give meaning to each word in the question. So they answer off the question. They should be able to write in isiXhosa or in English. And given more time. Questions should be set in both languages.

Language is the common factor in every teaching and learning situation. Transforming how it is used to enable an optimal learning environment is clearly the responsibility of every teacher, and every educational institution.

The narratives of examination assessment include fear, tension, doubt and stress. The language experience of Chuma proved most informative. Like Bongani, he translates the question from English into isiXhosa by picking on certain key words. He illustrated with the word 'overview', finding first other words equivalent to it in isiXhosa. Once established, he then goes back to the question and works out what he must do in his answer. He knows now that he must not give an in-depth answer, but he must focus on broad, holistic content. With the answer now conceived in his mind in isiXhosa, he translates it into English and then starts the actual writing of his answer. He points out that he picks only certain words, but like Bongani, his fear is that he might misunderstand what the question requires. Dumani calls this a frustrating moment, but he uses a different coping mechanism. He contextualises the word within the question and tries to move on with his answer.

What can the examiner take from the above coping mechanisms in order to streamline the assessment experience of the student? Perhaps Chuma provides the answer when he states that:
There's a conversation in isiXhosa in your head in order to answer an assign in English. The problem is not to Xhosalise the English. It's true that there is a whole lot that I am doing in isiXhosa in order for me to be proficient in English.

Chuma is pointing out that multilingualism is an integral part of the assessment process, that isiXhosa is an integral part of the student's answer that is written in English. The strength of the answer lies in how well you understand the same concepts in your mother-tongue.

The concept of situational benefits was raised by Chuma, whose experience as a teacher provided the following insights:

My belief is that matric results are not a true picture of what is happening. Advantaged schools score high. Our kids are 'Half deaf, half dumb.' They hear, but they don't hear it all. When it comes to answering, they can't say precisely what they want to say. At these multilingual schools, the children are taught and they play in English. They are informally learning the language, so there are situational benefits.

Assessment is also determined by the subject content being taught. The respondents' informal discussions exposed how they struggled with the content of the English linguistics modules, querying why they had to write examinations in such technical data, like phonetics, lexicography and morphology, when they would not use this in everyday practice. They were not against learning these as part of their broad knowledge curriculum, but questioned the validity of them being assessed under examination conditions. Assignments should be an alternative, with examinations challenging their ability to evaluate their current use of the English language. The focus on technical, linguistic competency has proved discouraging to students of English and African languages. Mkhize and \& Ndimande-Hlongwa [11:26] describe it as follows:

A further challenge arises from the fact that, in the past, African languages were taught from a purely linguistic perspective; this led to a loss of interest amongst students. As a result, very few students graduate with African language majors from South African universities and this is more so at the postgraduate level. It is thus important to revitalise interest in African languages, especially amongst native speakers, at both school and university levels.

Academic assessment is crucial for the positive self-concept of the student, and success means more than just getting a qualification. It also means career opportunities, economic growth and the upliftment from poverty for many young South Africans. 
The narratives of Asanda, Bongani, Chuma and Dumani expose their psychological response to language learning, and their acceptance that English is the language that will provide more opportunities for them. It should be noted that their English language usage in their narratives is their spontaneous response to questions presented to them, and should not be confused with the profundity of their personal experience of language learning. As stated, the focus is on the content told, rather than in the telling of the story [15]. When they had time to write and refine their assignments, their English language usage rose above their translation coping mechanism and they were able to write more competently. Answers to an assignment question on the strategic role of languages in the transformation of society prove this point. While flawed in some respects, their considered writing in the English language was evident. There is more evidence of grammatical competency and sequential reasoning. Meaning is not confused. Below are selected extracts from the answers submitted by the four students:

Asanda: How is an ordinary person supposed to give an opinion about the state of this country when they are excluded from the conversation in the first place? Asking how the senior citizens of this country are expected to listen to a president who speaks a foreign language in his State of the Nation Address (SONA) is a legitimate question. Can we now say that whatever decision made at the national level was made with the best interest of the poor and marginalized at heart? This country is violating the rights of the weak and vulnerable and it has failed its people in this regard.

Bongani: After 1994 SA was seen as a rainbow nation, meaning that all population groups were recognised by the new government. This therefore meant that the African languages had to be developed and promoted... Colonisation impacted negatively on the colonised, they are now undermining their languages, resulting in them undermining themselves.

Chuma: Even those in power right now seem to be basking in the sun of uncertainty as they select English as a major medium of instruction in schools they are designated to control. It has been aptly said that English today is a language of control, inclusion and exclusion. Persons who are not proficient in English struggle to participate and compete, thus staying disadvantaged.

Dumani: African students... struggle with language before they understand the content of the subject. The use of African languages is associated with inferiority and (being) uncivilized but the fact is, when you reject your own language who is going to love and promote it for you.

Consultation with their isiXhosa professor confirmed their competency in spoken and written activities in their mother tongue, despite not having formal qualifications in isiXhosa as an academic subject. Their confidence was evident, and even when the topic for discussion may have been unknown to them, they coped by moving from known anchorage points to the unknown concepts. He pointed out that they were conversationally fluent in isiXhosa, although they tended to code switch at times. Academically, they had to borrow and resort to coinage because of the lack of an equivalent term. They did not have adequate linguistic competence in English, possibly because of their poor reading culture and lack of exposure to English contexts.

\section{Transforming the Role of the Teacher in the Multilingual Classroom}

"Denying African learners and educators the opportunity to learn or teach in indigenous African languages amounts to a violation of their Constitutional rights; it also impinges on their academic freedom" Zeleza [17] in Mkhize \& Ndimande-Hlongwa [11:16].

The coping mechanisms employed by the four respondents suggest much to the teacher in a multilingual classroom.

- Determination and resilience to learn the English language, and to learn it correctly, emphasizes their attitude to its significance and economic status in 2017. This is an immediate strength in the teaching situation. Dumani accepts that it is the most important way to grow, while Asanda believes it dictates how far he can successfully go in life.

- Asanda and Chuma relate the critical importance of reading in English, with Chuma going as far as to state that his isiXhosa community is not a usually reading community: "We are not readers. Making our children to be readers will change everything. That's the turning point." Asanda helped himself by reading novels to improve his English vocabulary. Teachers should encourage reading for pleasure, give more reading tasks and acknowledge the determination displayed by the student. Instilling the culture of reading was also recommended by their isiXhosa professor who added, though, that it is late to start meaningful reading interventions at university. Linguistic competence in both languages should ideally be cultivated much earlier in one's schooling. Meaningful intervention in the use of language starts at 
primary school, with competent language teachers leading the process.

- Dumani pointed out how he benefits from the autocorrect feature on cell phones and computers. While this helps him to improve his English, he would like to see this feature in indigenous languages as well. His point has been validated somewhat in this study that multilingualism improves the application of English as a language of instruction and assessment. The more proficient one is in isiXhosa, the more one is able to translate and understand the meaning of words in English.

- $\quad$ Promoting multilingualism in all contexts should be the norm. Society is multilingual, so is the classroom. Dumani makes a valid point when he says that he uses his indigenous languages rather than English when travelling in South Africa. His aim is to protect and preserve these languages.

- More time to answer questions was supported by the respondents. This allows for working out the meaning of a question first. Chuma pointed out that English speakers benefit because they don't have to do this in the limited time frame of an examination.

The University of KwaZulu-Natal (UKZN) and Rhodes University have already initiated various interventions to enable a multilingual teaching and learning environment across all disciplines. isiZulu has become an integral part of UKZN's teaching, learning and research. Some modules are taught through dual medium instruction, rather than through English alone. Further supporting the use of African languages is the development of isiZulu dictionaries aimed at linguistic scholars and undergraduate students, together with a manual and CD to teach Basic isiZulu to all first year students. All undergraduate programmes include a module in isiZulu [11].

The nature, stature and scale of curriculum transformation practised by UKZN should be the norm across higher education institutions so as to support and dignify the learning environment of students like Asanda, Bongani, Chuma and Dumani. Individual teachers should start it within their own classrooms if the concept of promoting multilingualism has not yet been initiated. Team initiatives by teachers should be encouraged so that the movement is sustained, and activist teachers supported. It should be consistently remembered that colonialism has deprived African languages of their value, and people of their identities. It is now the teachers' duty to dignify the narratives of all students who pass by their hallowed classrooms.

Mkhize \& Ndimande-Hlongwa [11:30] make the following summarised recommendations to embed African languages into higher education:

- Academics should be rewarded for publishing in African languages, in local and regional journals.

- Students should be encouraged to write their academic theses in African languages, across all disciplines.

- All student assessments, both oral and written, should have the option of being conducted in African languages.

- Professional bodies should ensure that an African language module is a compulsory requirement of their programmes.

- Mother tongue language study should be carried through basic education up to Grade 12 level.

- Community engagement including students and staff should be integrated into the teaching and learning process.

- The study of African languages should be encouraged through bursaries.

Okal [12] recommends that African languages should be rejuvenated and adapted to reflect modern reality. The impact of colonial languages should be addressed through focus on the heritage of indigenous languages. It is through this that Africa Rising can become more than just a development slogan. Okal [12:227] adds that:

Multilingualism provides a competitive edge in today's job market. Besides the academic and professional credentials, employers also look for fluency in the desired languages as an added advantage. Therefore, being a multilingual is a plus to any job seeker in this millennium. This can only be realised if multilingualism is entrenched in the learning curriculum.

Foregrounding diversity as an asset, Tonkin [14:6] is aptly cited in Akeem's [2] paper:

The diversity of language is an asset: it helps build cohesion in small communities and sustains unique cultures, thereby bestowing distinctive identities on individuals and reducing alienation and homogenization. The rich variety of linguistic idioms carries with it an equally rich variety of cultural forms and ways of thought, and maintains for humankind a diversity of devices for coping with the uncertain challenges of human existence.

The narratives of the students exposed their very real issues with learning the English language - the language of the colonisers, the language of their future and the language of international economies. 
Their determination to learn the language alongside their isiXhosa is commendable, together with their acknowledgement that language acquisition is a long, continuing process that demands their time and commitment. As a teacher of the English language, much has been learned from students' narratives over the years, as well as from various colleagues teaching language and other subject modules. Recommendations to fellow teachers in the multilingual, diverse classroom would include:

- Inform your students of why you want to encourage multilingualism in the classroom.

- Ask your students of how they would like to use their mother-tongue to improve their academic performance in English.

- Ask your students for practical ways in which you can assist their language learning experience, and apply them.

- Use translation and interpreting to improve understanding.

- Immerse your student in as much reading as possible in both English and isiXhosa, from newspapers to textbooks.

- Create assessment grids that separate grades for content and language usage/rules.

- Encourage analysis of question and answer memos.

- Teach grammar rules, and how to apply them.

- Teach writing principles, and show how they are to be used in concise samples.

- Give constructive, detailed feedback on written and oral tasks.

- Encourage creative writing in all languages; read some out to affirm the student.

- Encourage the use of all languages in class and socially.

- Know the language learning narratives of your students.

- Learn the indigenous language of your students.

\section{Conclusion}

Acknowledging the personal and individual student experience of language is instructive for both educator and institution. The narratives of the four students speak directly to re-educating the teacher in terms of methodology, assessment and classroom interaction. The impact and presence of colonial constructs in all elements of the teaching situation exposes the critical need for transformation. This paper has relied on anti-colonial theory to expose the fallacy that competency in the language of the colonisers is the panacea to addressing diversity in the classroom. African languages are an integral part of the students' transformative and emancipatory experience. The application of narrative theory provided the evidence for this conclusion, illustrating the lived experience of real-life students in their individual language learning challenges. Their stories helped to make sense of themselves, and of others. Establishing their identity is core to their narrative, and provides direction to an educator in being sensitive to the inequality and injustice of the present language situation in teaching, learning and assessment. While the sample was limited to only four narratives, their content can be projected to represent almost every second language student being taught and assessed through the medium of one language, English. More such stories need to be heard. The discussion section of the paper provided further evidence that negotiating personal experience based on language has the potential for diverse pathways which would transform education in multilingual contexts. Notably, it was the students themselves who initiated recommendations for diverse didactical interventions and assessment formats. Further practical suggestions for teachers, from teachers conclude the paper.

The narratives of Asanda, Bongani, Chuma and Dumani have distinctive identities that need to be individually recognised. Their thinking in isiXhosa is equally important as their writing in English. Both languages sharpen the cognitive development of the other. Both languages should be valued and used in a multilingual teaching, learning and assessment situation.

\section{Reference}

[1]Aarikka-Stenroos, L. (2010) The contribution and challenges of narrative data in inter-organizational research, Paper delivered at the IMP Conference, Budapest,Hungary.https://impgroup.org/uploads/ papers/7553.pdf.(Accessed on 31 May 2017).

[2]Akeem, A.A. (2011) Language Barrier as the Bane of Development in Africa. Africana. June 2011.http:// africanajournal.org/wp-content/uploads/Language-Barrieras-the-Bane-of-Development-in-Africa-AFRICANAVol5-No2.pdf. (Accessed on 10 May 2017).

[3]Alexander, N. (2011) After Apartheid: the Language Question. In Shapiro Ian \& Tebeau Kahreen (ed): After Apartheid: Reinventing South Africa? University of VirginiaPress.http://elsinore.cis.yale.edu/macmillan/ apartheid/alexanderp2.pdf. (Accessed on 25 July 2016).

[4]Bruner, J. (1986) Actual minds, possible words.Harvard University Press, Cambridge.

[5]Dei, G.J.S. (2012a) Indigenous AnticolonialKnowledge as 'Heritage Knowledge' for Promoting Black/African Education in Diasporic Contexts. Decolonization:Indigeneity, Education \& Society 1,1: 102-119. 
[6]Dei, G.J.S. (2012b) Reclaiming our Africanness in theDiasporized Context: The Challenge of Asserting a CriticalAfrican Personality. The Journal of Pan African Studies4,10: 42-57. Department of Education (DoE).

[7]Elliott, J. (2005) Using narrative in social research:qualitative and quantitative approaches. London:Sage.

[8]Lyons, J. (1981). Language and Linguistics: AnIntroduction, Cambridge University Press, Cambridge,1981.

[9]Mangu, A.M. (2006). Democracy, African Intellectualsand African Renaissance. International Journal of AfricanRenaissance Studies - Multi-, InterandTransdisciplinarity 1,1: 147-163.

[10]Mishler, E.G. (1986) Research interviewing. Contextand Narrative. Harvard University Press, Cambridge.

[11]Mkhize, N. \& Ndimande-Hlongwa, N. (2014) AfricanLanguages, Indigenous Knowledge Systems (IKS) and the Transformation of the Humanities and Social Sciences inHigher Education. Alternation 21,2 (2014) 10 - 37 ISSN1023-1757.

[12]Okal, B.O. (2014) Benefits of Multilingualism inEducation. Universal Journal of Educational Research2(3): 223-229. http://www.hrpub.org Accessed on 10 May2017.

[13]Simkins, C., and A. Patterson. 2005. LearnerPerformance in South Africa: Social and EconomicDeterminants of Success in Language and Mathematics.Cape Town: HSRC Press.

[14]Tonkin, Humphrey (2003). Issues in GlobalEducation: Language and Society. Occasional Papers,American Forum for Global Education 178: 1-36.

$\begin{array}{lccc}\text { [15]Vincent, L. } & \begin{array}{l}\text { (2017). } \\ \text { Writing,Nelson }\end{array} & \text { Workshop on } & \text { Narrative } \\ \text { Mniversity, } & \text { Research }\end{array}$ CapacityDevelopment, Port Elizabeth.

[16]Wane, N.J. (2008) Mapping the Field of IndigenousKnowledges in Anticolonial Discourse: A TransformativeJourney in Education. Race Ethnicity and Education 11(2):183-197. July 2008.

[17]Zeleza, Paul Tiyambe. (2006) The Inventions ofAfrican Identities and Languages: The Discursive andDevelopmental Implications. In Selected Proceedings ofthe 36th Annual Conference on African Linguistics, ed.Olaoba F. Arasanyin and Michael A. Pemberton, 14-26.Somerville, MA: Cascadilla Proceedings Project. 